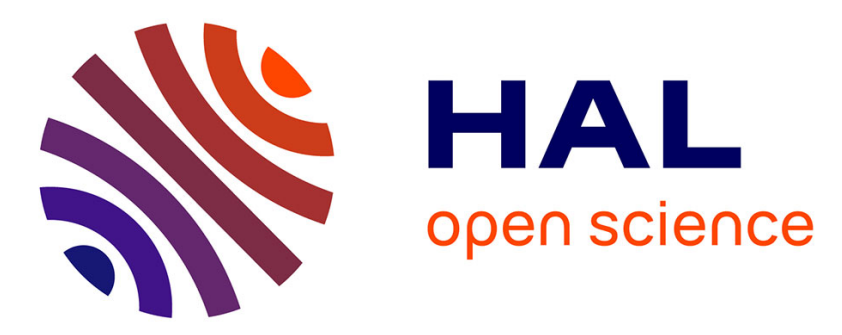

\title{
An original impact device for biomass characterisation: results obtained for spruce and poplar at different moisture contents
}

Floran Pierre, Giana Almeida, Françoise Huber, Philippe Jacquin, Patrick Perre

\section{To cite this version:}

Floran Pierre, Giana Almeida, Françoise Huber, Philippe Jacquin, Patrick Perre. An original impact device for biomass characterisation: results obtained for spruce and poplar at different moisture contents. Wood Science and Technology, 2013, 47 (3), pp.537-555. 10.1007/s00226-012-0512-9 . hal00818773

\section{HAL Id: hal-00818773 \\ https://hal-centralesupelec.archives-ouvertes.fr/hal-00818773}

Submitted on 29 Apr 2013

HAL is a multi-disciplinary open access archive for the deposit and dissemination of scientific research documents, whether they are published or not. The documents may come from teaching and research institutions in France or abroad, or from public or private research centers.
L'archive ouverte pluridisciplinaire HAL, est destinée au dépôt et à la diffusion de documents scientifiques de niveau recherche, publiés ou non, émanant des établissements d'enseignement et de recherche français ou étrangers, des laboratoires publics ou privés. 


\title{
An original impact device for biomass characterisation: results obtained for spruce and poplar at different moisture contents
}

\author{
Floran Pierre • Giana Almeida • Françoise Huber • \\ Philippe Jacquin - Patrick Perré
}

Received: 20 September 2011 / Published online: 16 October 2012

(C) Springer-Verlag Berlin Heidelberg 2012

\begin{abstract}
This paper describes an experimental device designed to determine the mechanical behaviour of lignocellulosic products subjected to high strain rates. This impact system consists of a moving trolley equipped with an accelerometer, which is thrown against a fixed trolley. The sample is attached to the fixed trolley, and the accelerations of both trolleys during the impact are analysed to obtain stress/strain curves. A high-speed camera synchronised with a high-powered xenon flash records up to 4,000 frames/s. A set of tests on wood samples is described to illustrate the potential of this new device. In particular, the cross-effects of compression rate and moisture content were demonstrated by performing both quasi-static $\left(1 \mathrm{~mm} \mathrm{~min}^{-1}\right.$ using a conventional testing machine) and dynamic tests $\left(1.7 \mathrm{~m} \mathrm{~s}^{-1}\right.$ using the impact device). Poplar and spruce samples, equilibrated at three different moisture contents (air-dried, fibre saturation point (FSP) and fully saturated), were tested. Two findings are particularly worthy of mentioning: (1) despite the plasticising role
\end{abstract}

Electronic supplementary material The online version of this article

(doi:10.1007/s00226-012-0512-9) contains supplementary material, which is available to authorized users.

F. Pierre $(\bowtie) \cdot$ P. Perré

LGPM, Ecole Centrale Paris, Grande Voie des Vignes,

92290 Châtenay-Malabry, France

e-mail: floran.pierre@ecp.fr

G. Almeida

UMR 1145 Ingénierie Procédés Aliments, AgroParisTech,

1 avenue des Olympiades, 91300 Massy, France

G. Almeida

UMR 1145 Ingénierie Procédés Aliments, INRA,

1 avenue des Olympiades, 91300 Massy, France

F. Huber · P. Jacquin

UMR 1092, LERFoB Bois Biomateriaux Biomasse Team, INRA, Nancy, France 
of water, the sample at FSP exhibited a fragile behaviour at the high compression rate, (2) the resistance due to the expulsion of water out of saturated samples can be assessed only by performing an impact test.

\section{Introduction}

Numerous studies have been carried out on the behaviour of wood under dynamic compression. One of the main reasons for this interest has come from the use of wood as an energy absorber in packaging (Adalian and Morlier 2002). Improvement of machining, either in terms of forces or surface quality, is another field which requires the investigation of the mechanical behaviour at high deformation rate (Eyma et al. 2005).

Different techniques have been conceived to perform dynamic tests. One of the most commonly used devices is the Drop Weight Test where a mass is raised to an initial height before being dropped onto a sample. Strain is determined by an accelerometer fixed to the mass or by laser sensor, while stress is determined by a load cell. According to the first law of thermodynamics, the high stress rate is given by the weight of the mass and the high strain rate is determined by the initial height (Wang et al. 1996; Mindess et al. 2004; Sukontasukkul and Lam 2004). The same principle is used in the Swinging Pendulum Machine, also called the Charpy or Izod machine. A swinging pendulum with accurately known weight and initial height hits a sample thereby causing high stress rates (Siewert and Schmieder 1995). Initial velocities in the range of $1-10 \mathrm{~m} \mathrm{~s}^{-1}$ can be obtained with this technique. If much higher strain rates are required, a method commonly used to study materials under high compression rates is the Split Hopkinson Pressure Bar. With this device, the sample is sandwiched between two bars. The high stress rate is generated by propagating a pulse to the sample using a drop weight fired from a gas gun which hits the first bar. Reid and Peng (1997) used this kind of device to determine the behaviour under impact of five wood species (balsa, yellow pine, redwood, American oak and ekki). The test species ranged in density from 260 to $1,200 \mathrm{~kg} / \mathrm{m}^{3}$ and were subjected to uniaxial compression under impact loading, at velocities in the range of 30-300 $\mathrm{m} \mathrm{s}^{-1}$. These authors showed, from the uniaxial impact tests, that the initial crushing stress of the wood sample increased significantly with an increase in impact velocity and therefore had repercussions on the energy absorption capacity of the wood. Also, the initial crushing stress was shown to be higher if the wood was tested along the grain. François (1992) used this kind of device to test poplar and redwood under impact, and his results showed, unexpectedly, that poplar wood presented a higher initial crushing stress which reflected its better energy absorption capacity.

The increasing interest in biomass as a source of renewable energy gives rise to a crucial demand to grind the raw product, as several industrial processes such as flash pyrolysis or gasification require powder. However, due to the resilience of lignocellulosic products, the energy consumed during grinding is unacceptable. Simple pre-conditioning treatments (e.g., thermal treatment) are promoted to reduce 
the amount of grinding energy, but a compromise is needed regarding the treatment intensity between benefits and detriments (loss of mass and energy content). For this reason, objective data are necessary to assess the benefit of such treatments or to tune their intensity. Experimental devices able to perform mechanical tests as close as possible to the grinding process are among possible answers (Tavares and King 1998).

This paper presents a new experimental device for determining wood grindability. The authors" design presents two main advantages over existing ones: its ability to test material over a large range of velocities and the observation of the structure evolution at the tissue level (cracks, deformation heterogeneity) during the impact thanks to a high-speed camera.

A full data set is presented and analysed in the second part of the paper namely the stress/strain curves and the images taken during the impact. For this purpose, poplar and spruce samples at different moisture contents (air-dried, equilibrated at the fibre saturation point and saturated) were tested in radial direction using two compression rates.

\section{Device conception}

\section{Experimental set-up}

The experimental device was made from aluminium alloy profiles from the Elcom company. It comprises two linear slides ( $2 \mathrm{~m}$ long, with a section of $80 \times 80 \mathrm{~mm}^{2}$ ) placed on three legs $\left(0.6 \mathrm{~m}\right.$ height, with a section of $\left.40 \times 80 \mathrm{~mm}^{2}\right)$ to ensure good stability. The distance between the two rails is kept constant by means of four spacer blocks. A photomicrosensor (OMRON model EE-SX473) is fixed on the testing ground close to the impact. The experimental set-up is presented in Fig. 1.

The moving trolley is propelled against the fixed trolley by means of a SMC CP95 pneumatic jack connected to a laboratory compressed air system. This pneumatic jack has an internal diameter of $32 \mathrm{~mm}$ and a maximal stroke of $250 \mathrm{~mm}$. The overpressure can range from 0.5 to $10 \mathrm{bar}$. An air container with a capacity of 121 (Reflex) is installed as damping volume to ensure better control of the pressure in the pneumatic jack when opening the valve. A manometer controls air pressure within the container, allowing selection of the trolley velocity at the end of the acceleration phase.

The two trolleys were constructed with aluminium alloy plates and consist of two Elcom double bearing units. Each has a concentric and eccentric double bearing unit which allows adjustment of the tight fit between the trolley and the guiding slides. Indeed, it is important to have as little friction as possible while maintaining a perfect guidance, as the moving trolley runs along the linear slides. A stainless steel mass of $2.68 \mathrm{~kg}$ is tightly fixed inside each trolley to obtain a total mass of $4.72 \mathrm{~kg}$. This design is symmetrical so that both trolleys, equipped with an accelerometer, can be set in motion. However, it is much more convenient, when using the highspeed camera, to fix one trolley and to throw the other against it. An optical target is 


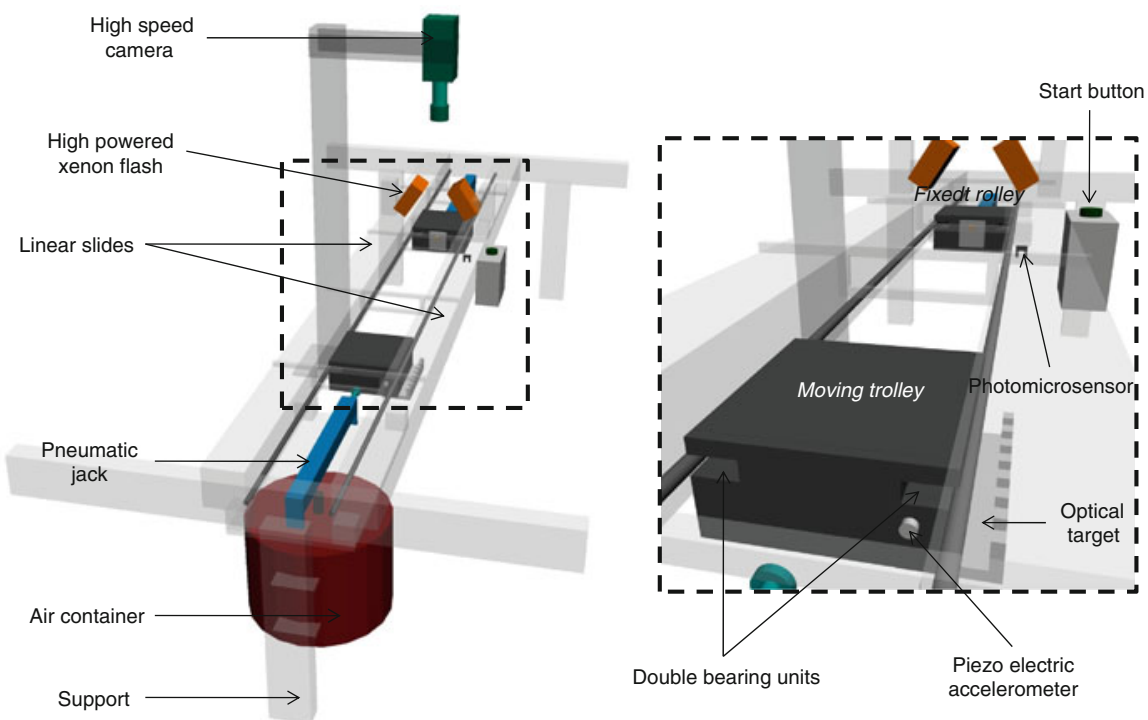

Fig. 1 Experimental set-up

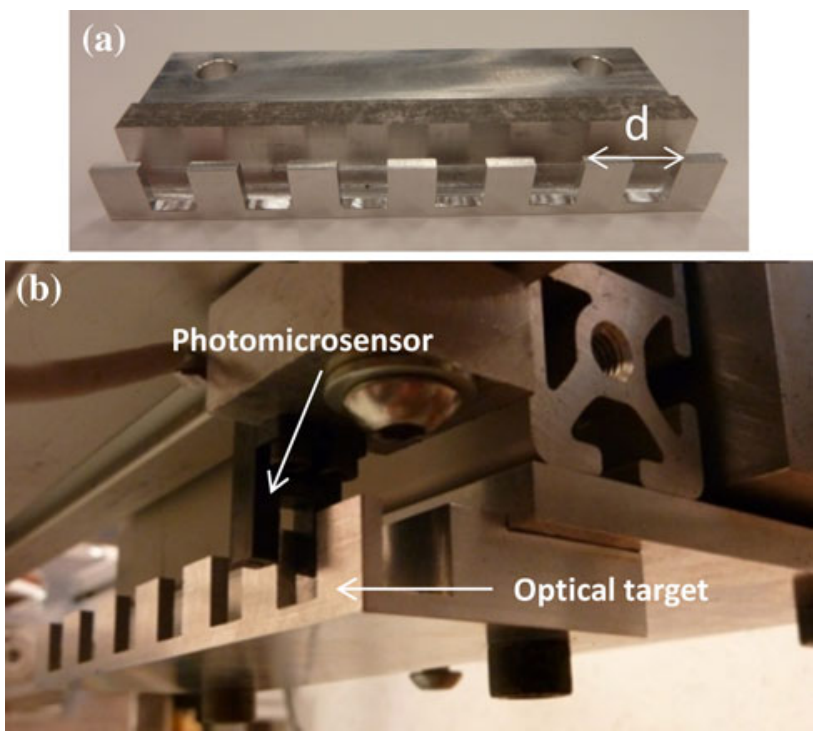

Fig. 2 a Optical target ( $d$ distance between two successive edges), b passage of the optical target through the photomicrosensor

positioned on the moving trolley so that it passes through the ray of the photomicrosensor (Fig. 2). This element is very important and must be machined with high precision to allow the strain field to be computed with accuracy. 
Data acquisition/collection

\section{Tension and acceleration}

A piezoelectric accelerometer $(D J B, A / 24 / E)$ is glued at the back side of the stainless steel mass to measure the acceleration throughout its movement, including the acceleration phase and the free translation. It has a sensitivity of $5.37 \mathrm{pC} / \mathrm{g}$ and can measure acceleration up to $105 \mathrm{~g}$. A charge amplifier converts the acceleration signal to a dynamic signal acquisition module (NI PCI-4462) with a 16 bits A/D converter. The accelerometer sensitivity and the gain $\times 1$ are set in the amplifier to ensure accurate conversion. The frequency range of the high pass filter $(0.1 \mathrm{~Hz})$ is switched on.

The dynamic signal acquisition module can record up to $204.8 \mathrm{k}$ samples per second on each of the four available acquisition channels. Only two channels were used for this work, one for acceleration, and one for the photomicrosensor. Acquisition is triggered as the first crenel of the optical target crosses the photomicrosensor. A buffer in the acquisition module saves any data collected before, which is then available in the acquisition file as "pre-trigger" data. Figure 3 gives an example of the raw data recorded during a typical test.

When a crenel of the optical target passes through the sensor, the tension falls to zero. Since the distance between the edges of two successive crenels is known with accuracy, the trolley velocity is simply given by:

$$
v=\frac{d}{\left(t_{2}-t_{1}\right)}
$$

where $v$ is the trolley velocity $\left(\mathrm{m} \mathrm{s}^{-1}\right), d$ is the distance between the edges of the first two crenels (m), $t_{1}$ is the time (s) at the end of the first crenel and $t_{2}$ the time (s) at the end of the second one.

It is important to note that two edges of the same sign were used (in this case, the descending edge) so that the signal is not affected by the size of the light beam of the photosensor. This is very important to ensure accurate velocity determination.

The acquisition module is driven by the LabView Signal Express software which allows parameters such as accelerometer sensitivity, triggering parameters, the number of acquisitions and the frequency of acquisition to be easily set. 140,000 pre-triggering data are also recorded.

\section{Image acquisition}

An AOS X-PRI high-speed camera is synchronised with a high-powered xenon flash (Lumix) compatible with the maximum frame rate of the camera $(4,000$ images per second). The flash power is about $30 \mathrm{~W}$, and up to 252 flashes can be delivered during a single acquisition. Image acquisition is also triggered when the first crenel passes through the photosensor.

Data analyses

The position of the moving trolley versus time is determined by a double integration of the acceleration: 

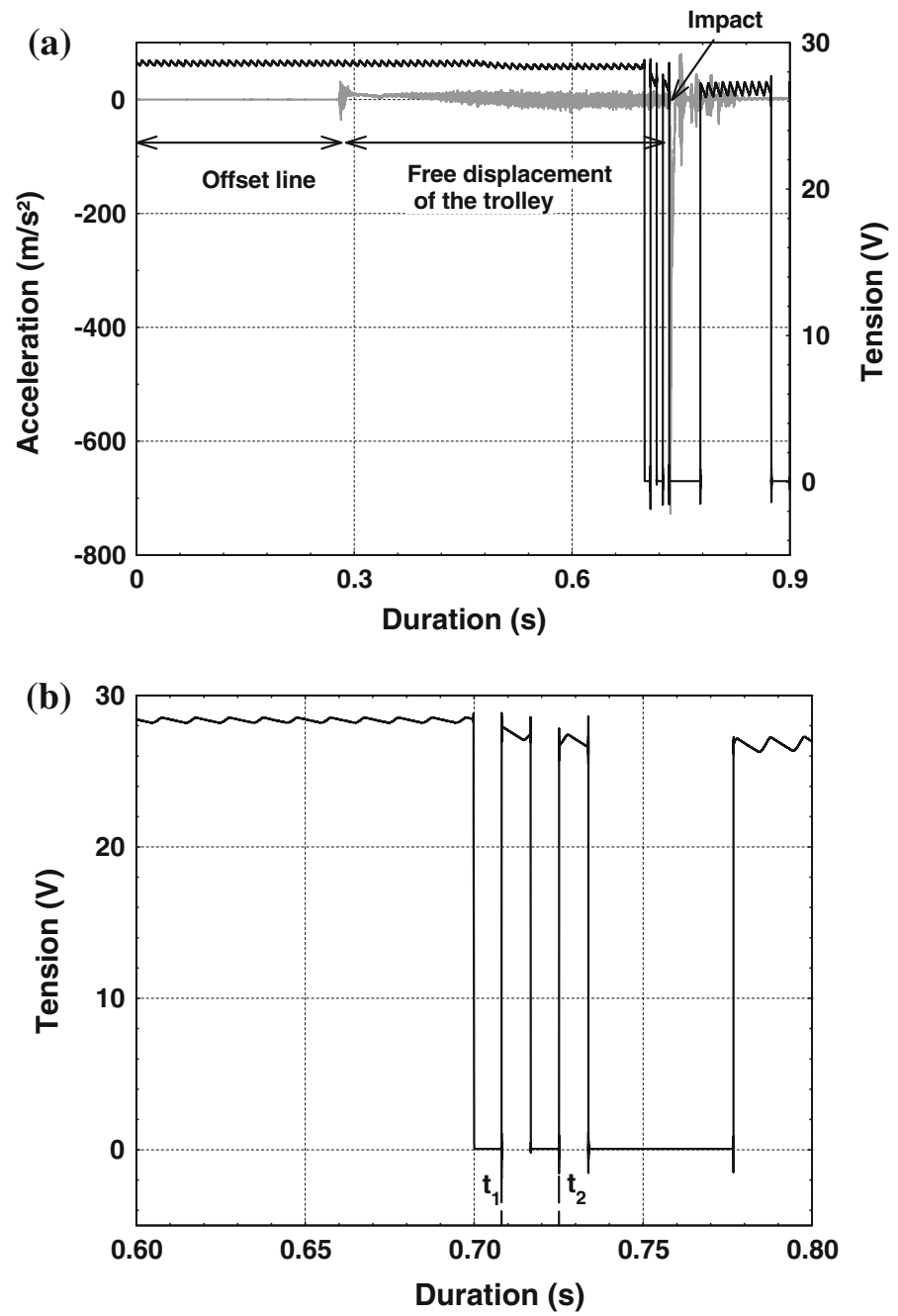

Fig. 3 Original data obtained during a test. Tension (black curves) and acceleration (grey curve) recorded during a test (a), with details of the photosensor signal used to determine the two instants $t_{1}$ and $t_{2}$ (b)

$$
a=\frac{\mathrm{d} v}{\mathrm{~d} t}=\frac{\mathrm{d}^{2} x}{\mathrm{~d} t^{2}}
$$

where $a$ is the trolley acceleration $\left(\mathrm{m} \mathrm{s}^{-2}\right), v$ is the trolley velocity $\left(\mathrm{m} \mathrm{s}^{-1}\right)$ and $x$ is the trolley position $(\mathrm{m})$.

The double integration is performed using the experimental data by using a development at the first order in $\mathrm{d} t$ for the velocity:

$$
\begin{aligned}
& v(t+\mathrm{d} t) \simeq v(t)+a(t) \times \mathrm{d} t \\
& x(t+\mathrm{d} t) \simeq x(t)+\frac{v(t+\mathrm{d} t)+v(t)}{2} \times \mathrm{d} t
\end{aligned}
$$


Note that $a$ is positive during trolley acceleration, becomes slightly negative during its free translation and presents huge negative values during the impact. $v$ is positive throughout the test, except at the very last instant when the trolley springs back. In the protocol, this change of sign was considered to mark the end of the test.

Unfortunately, the double acceleration of an experimental signal can lead to significant cumulative errors, particularly in terms of position. The first problem lies in the offset of the acceleration signal (Fig. 3a), which varies between different experiments. The acceleration signal needs to be adjusted by this offset in order to obtain accurate values. As mentioned in a previous paragraph, the pre-triggering acceleration can be recorded with the Labview Signal Express software. The offset line is obtained by recording the acceleration when the moving trolley is kept fixed, just before beginning the test. The mean acceleration is calculated from 1,000 points on the offset line, and this correction value is applied to the acceleration signal. A Visual Basic program (VB 6 ) has been developed which applies these signal processing operations automatically.

In spite of this precaution, any small error increases linearly with time for the velocity and as the time squared for the position. This problem was avoided by starting integration just before the impact, using the photosensor to determine the initial conditions (i.e., initial position when the trolley passes through the target and initial velocity by the time interval between two successive crenels). The integrated signal was then used to determine the initial velocity at the starting time of the test, characterised by the first negative peak of the acceleration, which marks the very beginning of the impact.

Afterwards, the results are systematically checked by determining the trolley velocity at impact, by means of image analysis. The distance between the moving trolley and the sample is measured by Image $J$ software on the last two pictures taken just before impact. The velocity is then simply computed from the known time interval between two images. This comparison tells us that the differences in velocity determined by the two methods remained below $4 \%$.

Applying Eq. (3) from this starting point increased by a large amount the precision of the trolley position during the impact and allows the strain $(\varepsilon)$ to be computed with accuracy, as the change in sample length in relation to its initial length:

$$
\begin{aligned}
& l(t+\mathrm{d} t)=l_{0}-x(t+\mathrm{d} t) \\
& \varepsilon(t+\mathrm{d} t)=\frac{l(t+\mathrm{d} t)-l_{0}}{l_{0}}
\end{aligned}
$$

where $x$ is the trolley position (m), $l$ is the sample length $(\mathrm{m}), l_{0}$ is the initial sample length $(\mathrm{m}), \sigma$ is the stress (MPa) and $\varepsilon$ is the strain (\%).

During the compression stage, the stress is simply the force divided by the section, where the force is the trolley mass times the acceleration:

$$
\sigma(t+\mathrm{d} t)=\frac{M \times a(t)}{S}
$$

where $M$ is the moving trolley mass $(\mathrm{kg}), a$ is the acceleration $\left(\mathrm{m} \mathrm{s}^{-2}\right)$ and $S$ is the sample surface where the load is applied $\left(\mathrm{m}^{2}\right)$. 
The stress/strain curve of the sample is obtained by computing the strain and stress for each experimental time using Eqs. (4)-(6).

Peak analysis

As the peaks on the stress/strain curve are indicators of the brittleness of the sample, a specific way of dealing with them has been devised, the idea being to report both peak number and intensity.

For this purpose, an algorithm was developed that scans all points on the stress/ strain curve. A new peak is defined when the stress level of the next point is smaller than the current point. From this current point, the algorithm continues to test successive points while the stress level continues to decrease. Once the lowest level has been attained, the amplitude of that peak is defined as the difference in the stress value at the current point minus the smallest value attained just before the stress increases again (Fig. 4). When all the peak magnitudes have been detected, they are sorted over the values ranging from $\mathrm{val}_{\min }$ to $\mathrm{val}_{\max }$ in a number $\mathrm{N}$ of categories, either on a linear or a logarithmic scale.

$\mathrm{val}_{\text {min }}$ is not necessarily the smallest peak value encountered in a given test. On the contrary, a threshold value can be chosen slightly higher than the noise level associated with the device. For dynamic compression tests, this noise value is assessed from the amplitude of the peaks obtained on the signal during free displacement of the moving trolley (Fig. 3a).

It is important to note that the resonance of the moving trolley, observed at the end of the test, is avoided by only considering data below $50 \%$ deformation.

Results of the peak analysis are presented as distribution curves. Each point of the curve represents the number of peaks found within the corresponding range of amplitude for an average of three repetitions.

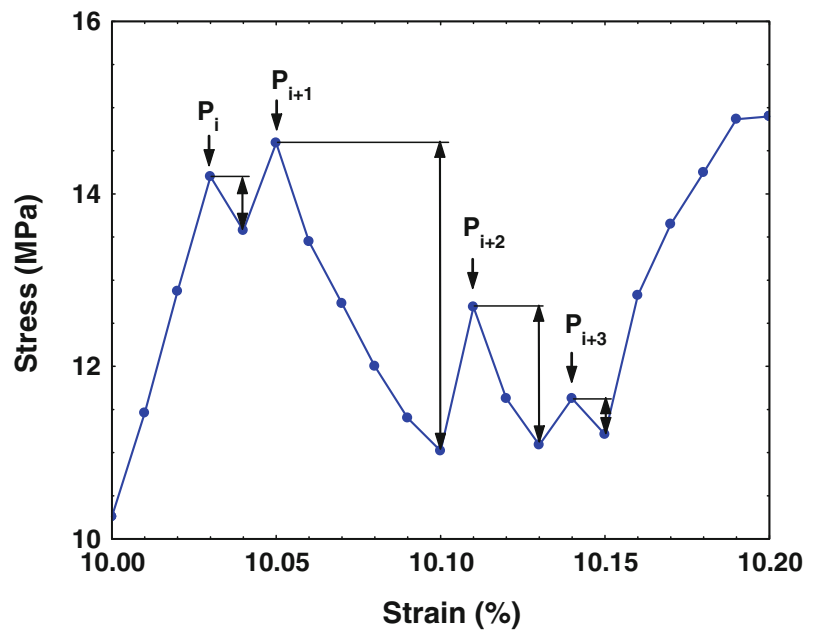

Fig. 4 Searching for peak number and magnitude: example for 4 successive peaks (the vertical double arrow line indicates the peak magnitude) 


\section{Results for wood samples at different moisture contents}

The above-described device was used to assess the influence of free and bound water on the behaviour of wood (poplar and spruce) by the mean of samples previously equilibrated at different moisture contents. Quasi-static tests were also performed on a conventional testing machine to emphasise the effect of the deformation rate.

\section{Materials and methods}

The wood samples tested in this study were obtained from a poplar tree (Populus euramericana $c v$. 1214), nearly 40 years old, from northern France (VillersCotterêts forest, Aisne) and a spruce tree (Picea excelsa), about 40 years old, from north-eastern France (Brun forest, Meurthe and Moselle). The average basic density of the wood samples (oven-dry mass to green volume) was $305 \mathrm{~kg} \mathrm{~m}^{-3}$ for poplar (coefficient of variation (CV) of $3 \%$ ), and $326 \mathrm{~kg} \mathrm{~m}^{-3}$ for spruce (CV of $6 \%$ ).

Defect-free blocks with a straight grain angle were cut in the longitudinal direction of the $\log$. Paired cubic samples with dimensions of $10 \times 10 \times 10 \mathrm{~mm}^{3}$ $(\mathrm{R}, \mathrm{T}, \mathrm{L})$ were carefully sliced from these blocks using a diamond wire saw (Well 3241). The active part of this saw consisted of a high tensile core wire $0.3 \mathrm{~mm}$ in diameter, impregnated with diamond grits to allow very gentle cutting. The wire winds and unwinds on two bobbins. A thread system ensures that the wire remains perfectly vertical as it moves. The stress level is minimised by cutting at a constant load (Perré 2007). The upper surface of each sample was prepared for observation using a slide microtome (Microm HM 440E). All samples had the same number and width of latewood rings.

The samples were then stored under three different conditions to produce different moisture contents. Six air-dried poplar and spruce samples were obtained by storing the samples for 7 days in the laboratory environment. Three poplar and spruce samples were stored in a sealed chamber, just above water, for 51 days to obtain samples at fibre saturation point (FSP). Finally, six poplar and spruce samples were immersed in water with vacuum cycles until saturation.

After moisture conditioning, the impact device was used to test the samples at high compression rates in a radial direction. The impact velocity was around $1.7 \mathrm{~m} \mathrm{~s}^{-1}$. The influence of compression rate on the mechanical behaviour of the wood was further determined by compressing air-dried and saturated samples at a low rate $\left(1 \mathrm{~mm} \mathrm{~min}^{-1}\right)$ using a quasi-static compression test (Davenport Nene).

In the quasi-static test, the modulus of elasticity (MOE) was determined as the slope of the linear part of the stress/strain curve. However, in the case of impact tests, this simple determination fails due to the more complex shape of the curve. The MOE was therefore determined as the slope of a straight line drawn from the origin to the maximum stress level observed at the beginning of the compression plateau (Fig. 5). The stress level of the compression plateau, for both the quasistatic and impact tests, was determined as the average stress level over the 25-35\% strain interval. 
Results and discussion

The images of the sample surface grabbed during the test are highly informative and worth an initial qualitative analysis. Figure 6 presents a selection of images taken during a quasi-static test of spruce in radial direction. The elastic deformation, which occurs at the very beginning of the test, is not clearly visible in these pictures due to the low level of strain. However, as expected, the images collected during the large deformation phase depict a clear effect of the moisture content.

In the case of cellular products under compression, the elastic deformation is usually followed by an inelastic domain which results from collapse and gross deformation of the cell (Easterling et al. 1982). This leads to a plateau on the stress/ strain curve. For air-dried samples, this inelastic deformation starts in the weakest part of the sample (earlywood) and is visible as a lighter zone produced by the cooperative collapse of all cells in this zone. As the load progresses, all the earlywood layers of the sample collapse successively until all the cell lumens have disappeared (Fig. 6a: pictures 2-4). Due to the heterogeneous density of wood within the annual ring, hence a heterogeneous rigidity, the compression strain decreases rapidly from earlywood to latewood. This deformation gradient in turn produces a contrast in the Poisson's effect in the direction perpendicular to the displacement, clearly visible on the sample edges at the very beginning of the earlywood layer, where the wood density suddenly drops by a typical factor of three (from c.a. $1,000 \mathrm{~kg} \mathrm{~m}^{-3}$ down to c.a. $300 \mathrm{~kg} \mathrm{~m}^{-3}$ ). The tangential deformation due to the Poisson's effect is therefore much higher in earlywood than in latewood: this gives rise to tangential stress, tension in latewood and compression in earlywood. At the very end of the test, this field is enough to produce some fractures in the zones under tension (Fig. 6a: pictures 5 and 6).

The role of water as a plasticising agent in wood has been widely reported (Goring 1963; Irvine 1984; Dumail and Salmen 1997; Placet et al. 2008). The

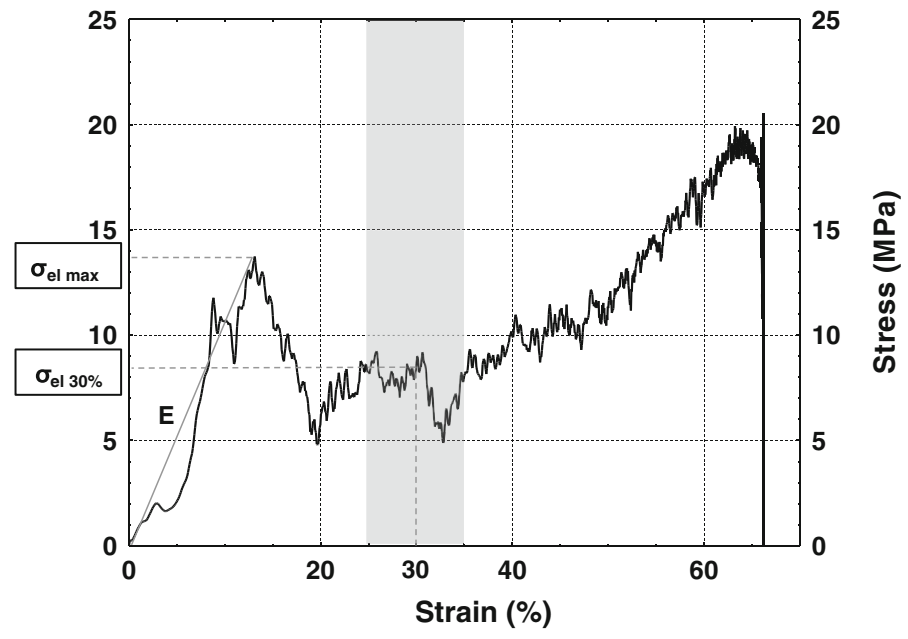

Fig. 5 Determination of some mechanical properties 
(a)

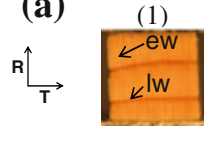

0

(b)
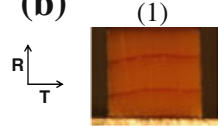

$0 \mathrm{~s}$

(2)

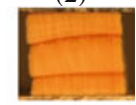

$29 \mathrm{~s}$

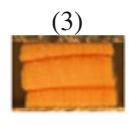

$63 \mathrm{~s}$

(3)

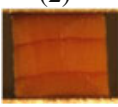

$13 \mathrm{~s}$

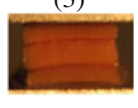

$53 \mathrm{~s}$

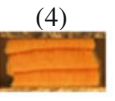

$100 \mathrm{~s}$

(4)

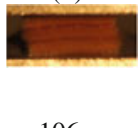

(5)

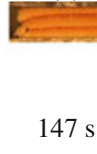

(5)

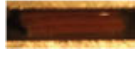

$136 \mathrm{~s}$

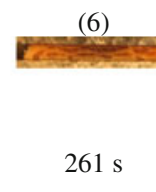

(6)

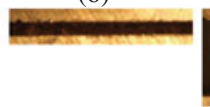

$218 \mathrm{~s}$
(7)

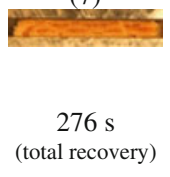

(7)

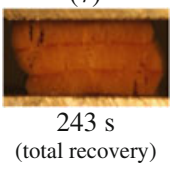

Fig. 6 Deformation of a air-dried and $\mathbf{b}$ saturated spruce during quasi-static compression ( $\mathrm{ew}$ earlywood, lw latewood)

presence of bound water in the cell wall basically activates the viscoelastic behaviour, hence the viscoelastic creep, namely in the case of quasi-static tests. This explains why the saturated sample is compressed to a thinner final thickness (Fig. 6b: picture 6) and presents a high resilience, which enables the sample to depict an impressive recovery (Fig. 6b: picture 7). Contrary to the air-dried samples, very few fractures appeared during compression. Because the sample was fully saturated, free water is ejected from the pore network throughout the compression plateau.

The images obtained with poplar are not presented here, as they depict the same trends.

Some of these observations are strongly tied to the coupled features of the cellular structure of wood and the cell wall composition. It is thus not surprising to observe some similarities during impact tests. For example, the effect of density heterogeneity in softwood produces similar effects: the earlywood zones deform first (Figs. 7, 8), starting from the less dense part of each annual ring (the wood formed in spring just after the latewood part of the previous ring) towards the end of the annual ring. This becomes evident on the air-dried sample, where the progression of the collapsed zone can be identified by its lighter colour (i.e., pictures $2-5$ in Fig. 7). Once the structure is fully collapsed, a steeper slope appears in the stress/strain curve, because the porosity can hardly reduce further. At the end of the test, the two masses move closer and closer, which forces the sample to spread perpendicularly and some cracks may appear along the radial direction (arrow in Fig. 8). These phenomena are impossible to observe in the case of fully saturated samples due to the spectacular expulsion of water (Figs. 7, 8). However, the final picture, obtained after recovery when the expulsion of water stopped, tells us that the overpressure of water was high enough to produce large cracks at c.a. $45^{\circ}$, never observed for the other tests. This kind of damage is similar to what can be observed during the drying of wood with internal heating (Perré and Turner 1999). The test at FSP seems to present a behaviour similar to that of the air-dried state. Nevertheless, thanks to the softening effect caused by the large amount of bound water, the higher resilience gives rise to obvious differences: (1) the absence of 
cracks, (2) a smaller minimal gap between the two masses and (3) the better recovery after the test (Fig. 7: picture 7).

Fortified by these observations, it can be now shifted towards quantitative data. Figure 9 depicts the stress/strain curve obtained during the impact test on air-dried spruce. Some events were selected on this curve with the corresponding images. Up to c.a. $10 \%$ strain, the stress signal remains monotonic and the deformation is too small to be apparent on the images. At $10 \%$ strain, an initial peak is clearly apparent, which corresponds to the collaborative buckling of the radial cell walls in the weakest layer of earlywood (in the present test, in the second growth ring, Fig. 9: picture 2). Once initiated, this mechanism produces a collaborative collapse, which expands within the ring and provokes a clear decrease of the stress level over a strain interval ranging from c.a. 12-20\%. Note the collection of small peaks that is superimposed on this general trend. When the deformation is around $30 \%$, the earlywood in the second growth ring is fully collapsed and the same mechanism occurs in the first ring (Fig. 9: picture 3), leading to a second decrease of the stress curve. From about $45 \%$ onwards, the earlywood has almost completely collapsed and the stress is increasing rapidly, due to the absence of a readily deformed pore network (Fig. 9: pictures 4-6).

Figures 10 and 11 summarise the stress/strain curves obtained for all tests, for spruce and poplar, respectively. Some impact curves depict a zone with large and rapid variations of the stress level at the end of the densification zone. This is indeed due to the resonance of the moving mass when the sample rigidity is too large. Similar responses obtained during tests without sample and the characteristic time of the acoustic wave along the moving mass confirmed this assumption. Anyway, this resonance phenomenon arises at the end of the compression plateau and does not influence the results analysis.

Globally, the whole set of curves depicts a clear effect of both moisture content and compression rates. Except at the very beginning of the compression plateau, the quasistatic tests always exhibit "smooth" curves, which allow the effect of bound water content to be clearly depicted: both the rigidity and resistance during the compression plateau decrease significantly with the increase in moisture content (Table 1):

- The stiffness is reduced by about $82 \%$ in spruce and by about $70 \%$ in poplar.

- The stress level is reduced by about $66 \%$ in spruce and $63 \%$ in poplar.

These observations are in agreement with literature data, which report an effect of moisture content on the mechanical properties only below the fibre saturation point (Gerhards 1982; Almeida and Hernández 2006). It is indeed well-known that water molecules bound to macromolecules play a plasticiser role, which activates the viscoelastic behaviour, known as hygro-activation (Göring 1963; Irvine 1984). Hemicelluloses, which are the most hydrophilic components, are most affected, and their softening temperature can be close to ambient temperature if the moisture content is sufficiently high. The softening temperature of lignin is strongly affected by a very small quantity of water. It can fall to $70{ }^{\circ} \mathrm{C}$ for hardwoods and c.a. $85^{\circ} \mathrm{C}$ for softwoods when subjected to very low frequencies (Placet et al. 2007). On the other hand, the softening temperature of cellulose is not affected by the moisture content (Göring 1963). 


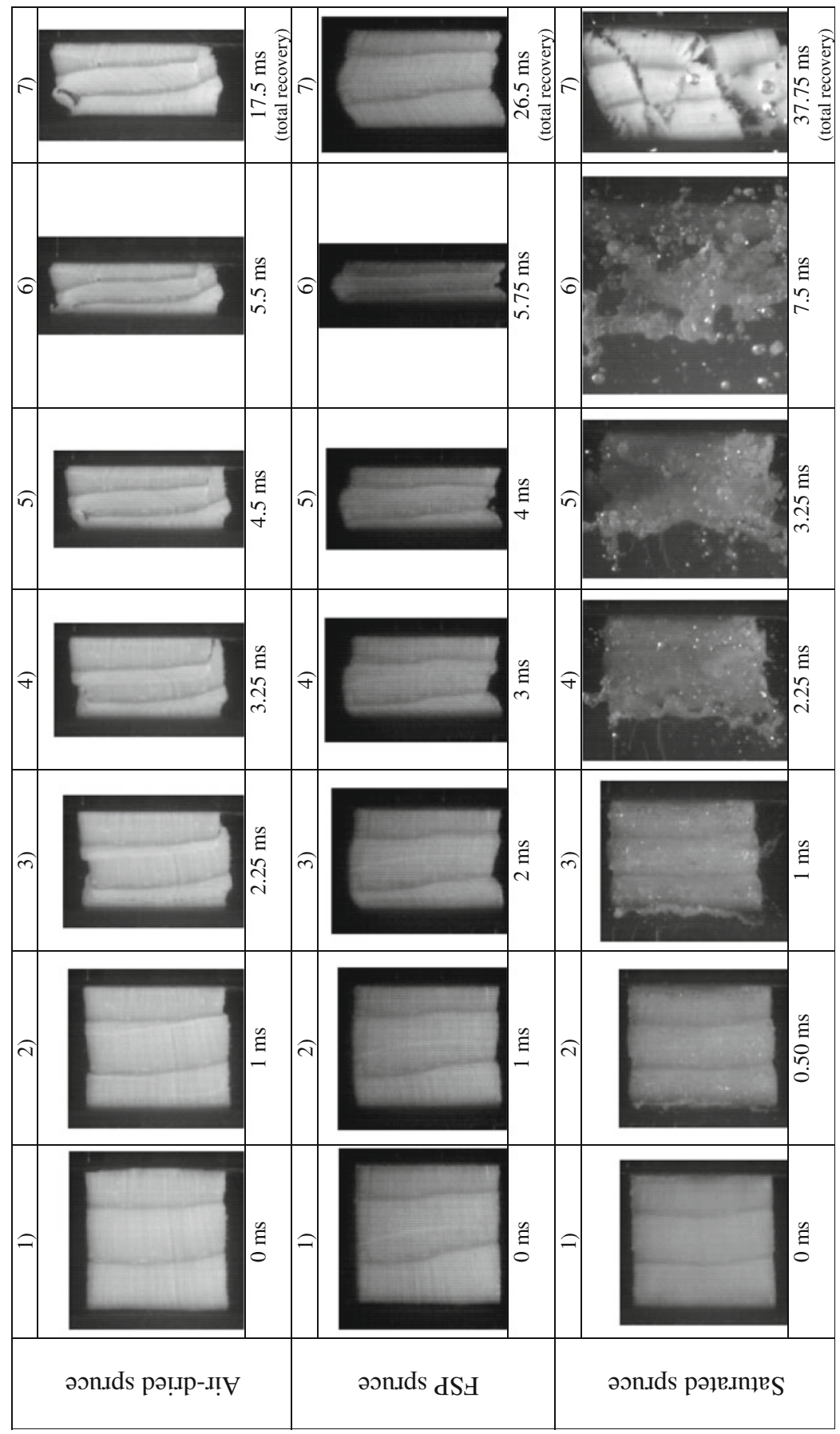

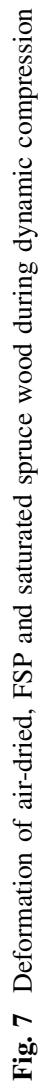




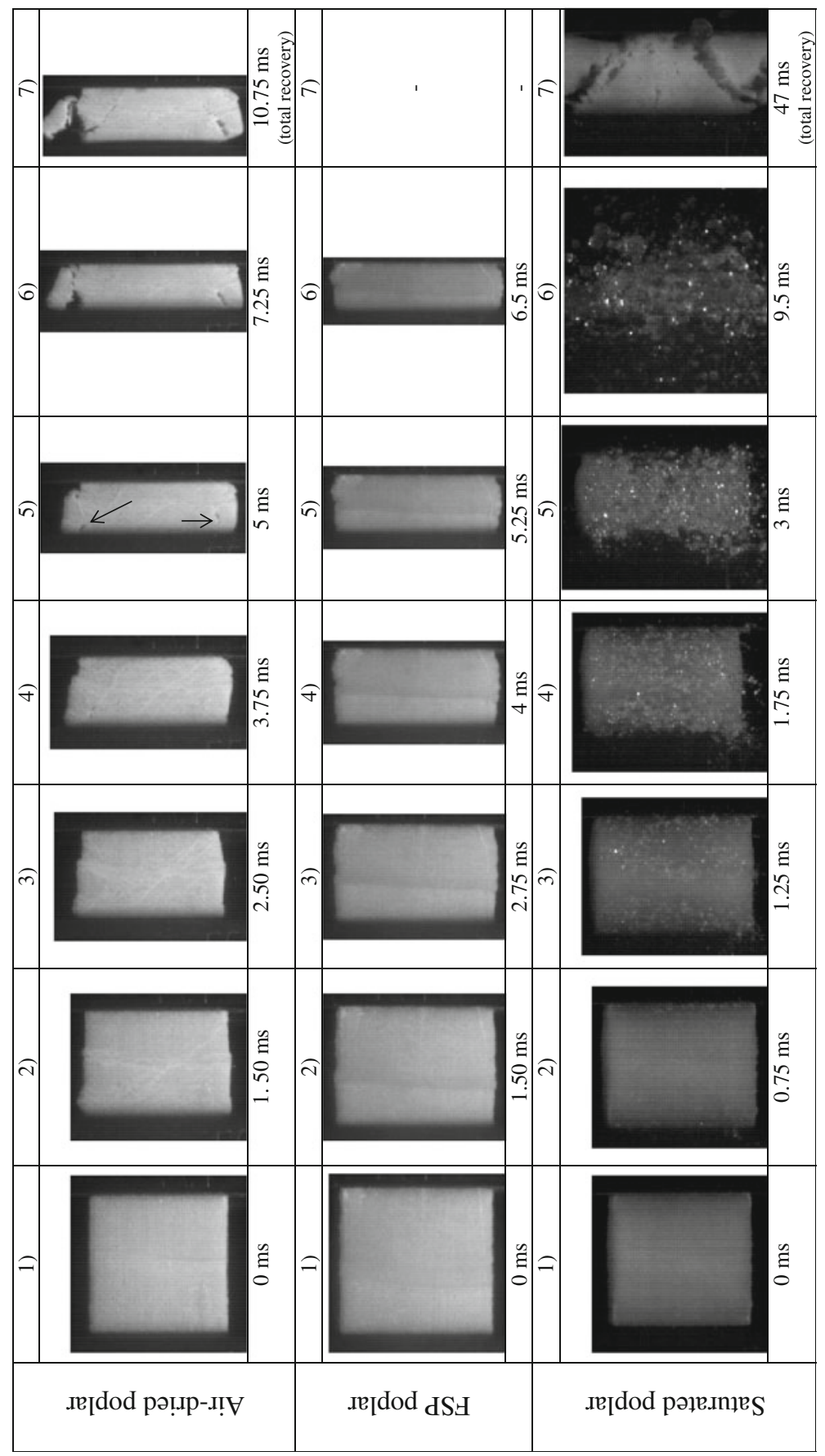

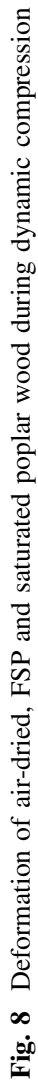




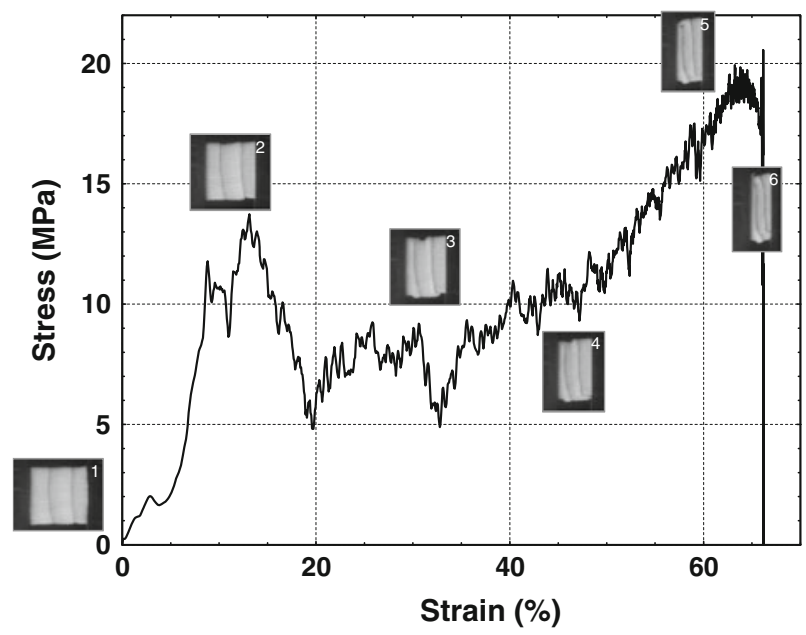

Fig. 9 Correlation between curve and images during an impact test (air-dried spruce)

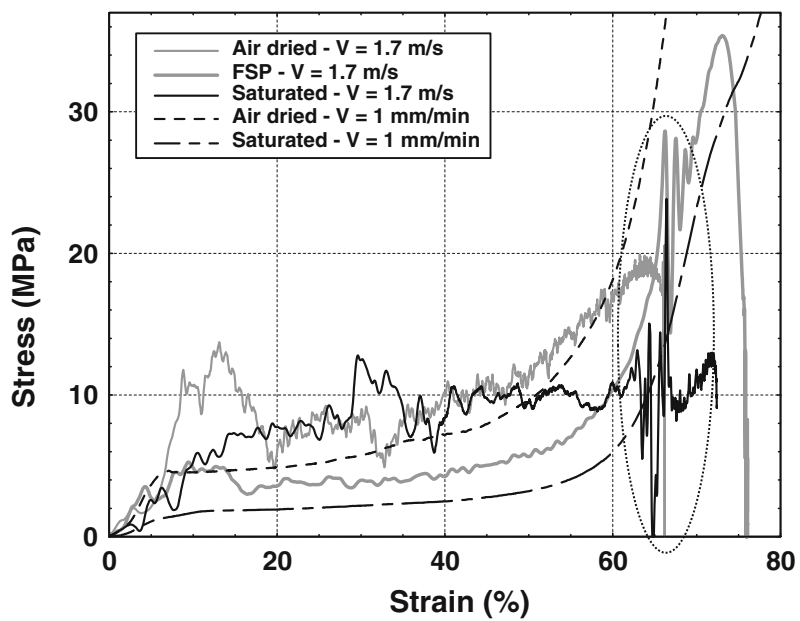

Fig. 10 Mechanical behaviour of spruce at different moisture contents for quasi-static and impact tests. The resonance of the moving mass is highlighted by a circle at the end of the compression plateau

This general trend is globally confirmed by the impact tests. The decrease due to the content of bound water, from air-dried to FSP, was however smaller than that observed at low compression rates. This indicates that the benefit of hygroactivation is counterbalanced by the reduced creep time allowed in this case of high deformation rate. The stiffness of saturated samples was reduced by c;a. $48 \%$ for spruce and $50 \%$ for poplar (Table 1) compared to air-dried samples. The stress level during the plastic-collapse domain was significantly lower for the sample at FSP than for the air-dried sample. This value was reduced by about $48 \%$ for spruce and by $43 \%$ for poplar (Table 1 ). 


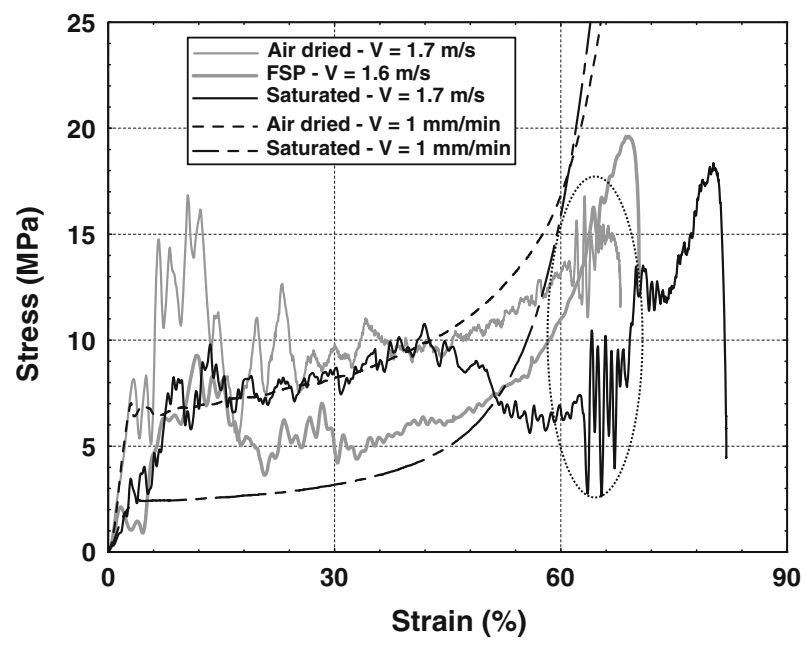

Fig. 11 Mechanical behaviour of poplar at different moisture contents for quasi-static and impact tests. The resonance of the moving mass is highlighted by a circle at the end of the compression plateau

Contrary to what is observed in quasi-static tests, this trend was not confirmed for the fully saturated samples which present a stress level in the plastic-collapse domain of the same order of magnitude as for the air-dried samples. In the case of saturated wood, the cell collapse dramatically reduced the wood porosity and obliged the free water to leave the pore network. When the deformation rate is important, the apparent stress is increased by the overpressure required for a viscous flow as a result of Darcy's law. This contribution becomes of major importance for saturated samples subjected to high compression rates, namely during the compression plateau (Widehammar 2004). These authors used the Hopkinson bars system and fully saturated samples. With very high deformation rates, water acts as a solid material, which directly contributes to sample resistance. In the case here, the deformation rate is such that this effect compensates almost exactly for the decrease in cell wall stiffness during the plateau.

However, concerning the stiffness determined at the early stages of deformation, the results (Table 1) are not in agreement with those reported by Renaud et al. (1996), who observed an increase in stiffness at increasing moisture content. The explanation might be due to the difference in the deformation rate, which is much higher with the Hopkinson bars.

In order to further analyse the curve shapes obtained in the impact tests, the peak analysis was performed as described in the Materials and methods section. Figure 12 depicts the peaks distribution in terms of amplitude for spruce and poplar at different moisture contents. For poplar, the effect of moisture content is clearly apparent. Air-dried samples present a few peaks with high amplitude whereas saturated samples have numerous peaks of low amplitude. FSP samples seem to show intermediate behaviour. Globally, spruce exhibits a similar behaviour. As main difference, it is interesting to note the curve shifted to the left (more peaks of 


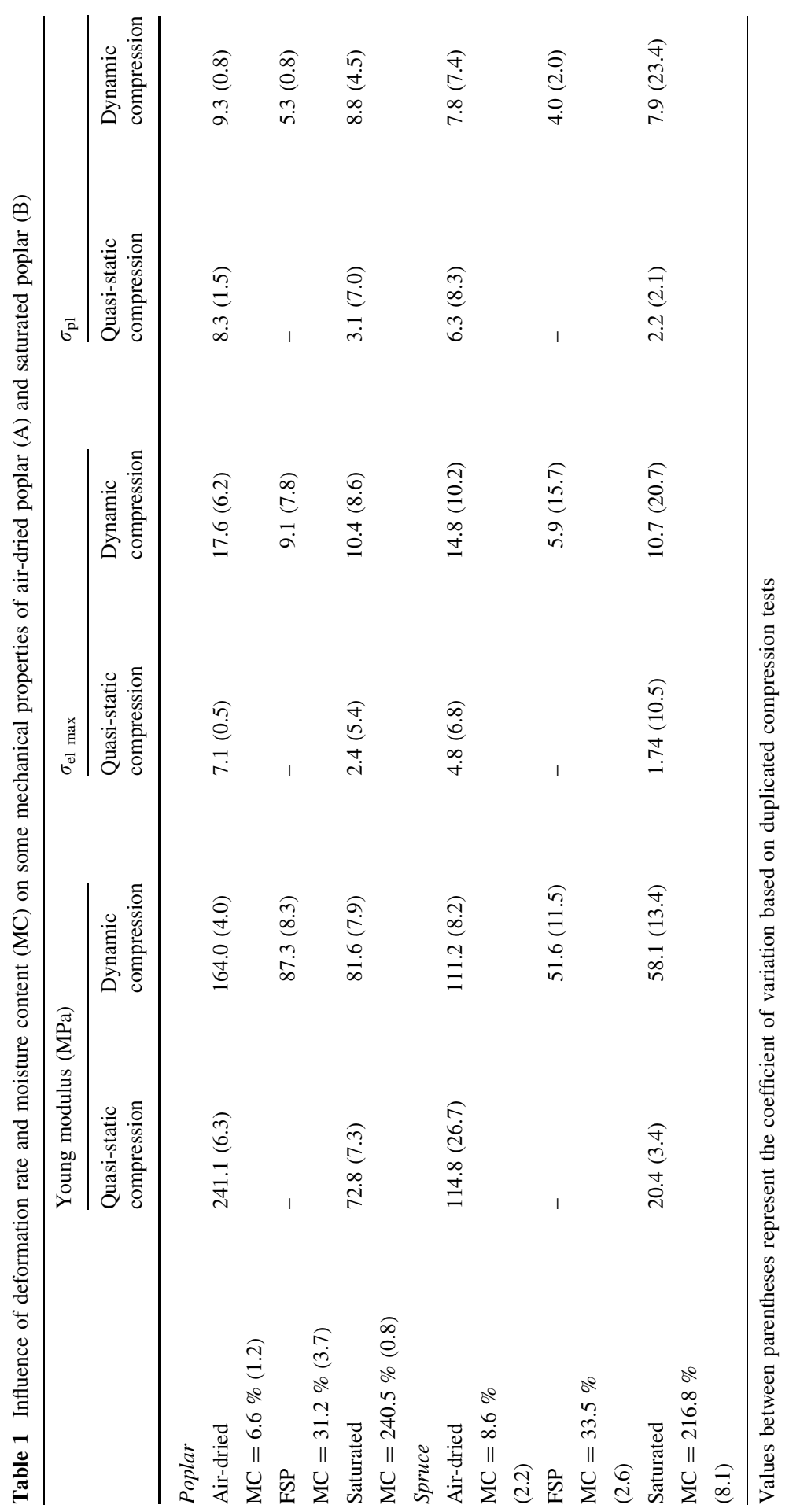




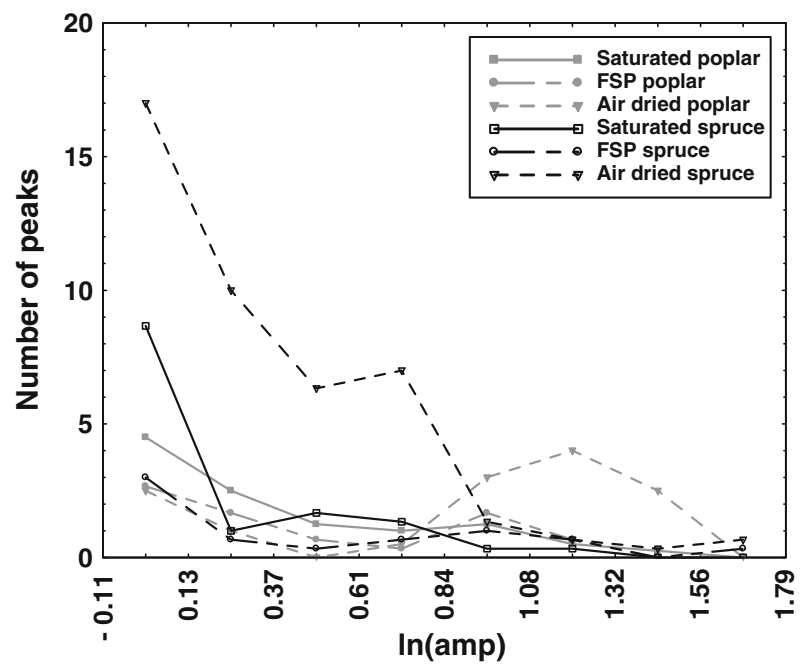

Fig. 12 Peak analysis (number of peaks as a function of its amplitude) of spruce and poplar at different moisture contents

smaller amplitude) for air-dried spruce compared to air-dried poplar. The anatomical features can explain this difference:

- In the case of poplar, the vessels represent large zones of low mechanical resistance. When collapse occurs in one vessel or in a small set of nearby vessels, a single peak of large amplitude appears.

- In the case of spruce, the relaxation of the stress field is due to a collaborative collapse of a whole line of tracheid. At each line corresponds one peak of moderate amplitude (Fig. 9).

\section{Conclusion}

An original impact device was developed, built and applied to determine the effect of moisture content on two wood species, poplar and spruce. Compared to existing devices, the recent design presents the advantages of testing material under a large range of velocities and providing information about the sample surface during impact thanks to a high-speed camera. The wood samples tested in this work were equilibrated at three different moisture contents: air-dried, equilibrated at FSP and fully saturated. The effect of the deformation rate was assessed by performing quasi-static tests on matched samples.

As expected, both series of tests (impact and quasi-static) emphasised the softening effect of bound water on the mechanical behaviour of wood. The influence of free water was significant only at high compression rates. In this case, free water cannot easily flow out of the sample during the compression plateau. The water is then under pressure, which increases the global stress level measured on the sample 
surfaces. For each moisture content, the results always depicted an increase in sample brittleness with an increase in compression rate.

These preliminary results highlight the potential of this new device. It can be used to study other porous materials, including other types of biomass. It is currently being used to assess the grindability of heat-treated wood.

Acknowledgments This work was financially supported by the ANR project TORBIGAP. The authors are grateful to the personnel of the LERFoB 3B team.

\section{References}

Adalian C, Morlier P (2002) "WOOD MODEL" for the dynamic behaviour of wood in multiaxial compression. Holz Roh- Werkst 60:433-439

Almeida G, Hernández RE (2006) Changes in physical properties of yellow birch below and above the fiber saturation point. Wood Fiber Sci 38(1):74-83

Dumail JF, Salmèn L (1997) Compression behavior of saturated wood perpendicular to grain under large deformations. Holzforschung 51(4):296-302

Easterling KE, Harrysson R, Gibson LJ, Ashby MF (1982) On the mechanics of balsa and other woods. Proceed R Soc Lond A 383:31-41

Eyma F, Méausoone PJ, Larricq P, Marchal R (2005) Utilization of a dynamometric pendulum to estimate cutting forces involved during routing. Comparison with actual calculated values. Ann For Sci 62:441-447

François P (1992) Plasticity of wood in multiaxial compression: application to the absorption of the mechanical energy (in French) thesis, l'Université Bordeaux I

Gerhards CC (1982) Effect of moisture content and temperature on the mechanical properties of wood: an analysis of immediate effects. Wood Fiber 14(1):4-36

Goring DAI (1963) Thermal softening of lignin, hemicellulose and cellulose. Pulp and Paper Canada Magazine T517-T527

Irvine GM (1984) The glass transitions of lignin and hemicellulose and their measurement by differential thermal analysis. Tappi J 67(5):118-121

Mindess S, Sukontasukkul P, Lam F (2004) Fracture of air-dried and fully saturated parallel strand lumber (PSL) under impact loading. Wood Sci Technol 38:227-235

Perré P (2007) Experimental device for the accurate determination of wood-water relations on microsamples. Holzforschung 61:419-429

Perré P, Turner IW (1999) The use of numerical simulation as a cognitive tool for studying the microwave drying of softwood in an over-sized waveguide. Wood Sci Technol 33:445-464

Placet V, Passard J, Perré P (2007) Differences of the viscoelastic properties of normal and reaction green wood across the grain measured by harmonic tests in the range of $0{ }^{\circ} \mathrm{C}$ to $95{ }^{\circ} \mathrm{C}$. Holzforschung 61:548-557

Placet V, Passard J, Perré P (2008) Viscoelastic properties of wood across the grain measured under watersaturated conditions up to $135^{\circ} \mathrm{C}$ : evidence of thermal degradation. J Mater Sci 43:3210-3217

Reid SR, Peng C (1997) Dynamic uniaxial crushing of wood. Int J Impact Eng 19(5-6):531-570

Renaud M, Rueff M, Rocaboy AC (1996) Mechanical behaviour of saturated wood under compression. Part 1: behaviour of wood at high rates of strain. Wood Sci Technol 30:153-164

Siewert TA, Schmieder K (1995) Pendulum impact machines: procedures and specimens for verification. ASTM publications, Philadelphia

Sukontasukkul P, Lam F (2004) Effect of tup geometry on impact behaviour of parallel strand lumber (PSL). J KMITNB 14(2):1-7

Tavares LM, King RP (1998) Single-particle fracture under impact loading. Int J Miner Process 54:1-28

Wang N, Mindess S, Ko K (1996) Fibre reinforced concrete beams under impact loading. Cement Concrete Res 26(3):363-376

Widehammar S (2004) Stress-strain relationships for spruce wood: influence of strain rate, moisture content and loading direction. Exp Mech 44(1):44-48 